\title{
La experiencia originaria del ser humano en el mundo y su relevancia para el quehacer científico, según Causalidad Psíquica de Edith Stein
}

\author{
ANNELIESE MEIS* \\ Facultad de Teología \\ Pontificia Universidad Católica de Chile (Chile) \\ ameis@uc.cl
}

\section{Resumen}

El presente estudio investiga la importancia de la "experiencia originaria" husserliana para la comprensión del conflicto de las ciencias exactas con el problema de Dios, que Edith Stein califica de "angustia inconsciente de encontrarse" con Él. A través de su controversia con la Psicología del siglo XIX, la discípula de Husserl muestra en su obra Causalidad Psíquica que hace falta un adecuado conocimiento de la índole propia de la ciencia para remontar con rigor metódico a la originariedad de la experiencia humana y el Dios presente allí. Esto conducirá a la ciencia al descubrimiento de su propia identidad por la superación del bloqueo consciente o inconsciente ante la revelación de Dios en el alma humana. De ahí que el presente estudio ofrezca un aporte relevante para la dilucidación filosófica de una cuestión teológica candente hoy - aporte logrado a través de un esfuerzo interdisciplinario arduo.

Palabras claves: Experiencia originaria, angustia, Dios, ciencia, Edith Stein.

\section{The experience of the human being in the world and its relevance to scientific work, according to Psychic Causality of Edith Stein}

\begin{abstract}
The present study investigates the importance of the Husserlian "originary experience" for the understanding of the conflict of the exacts sciences with the problem of God, which Edith Stein describes as "unconscious anguish of being" with Him. Through her controversy with of the 19th century Psychology, the disciple of Husserl shows in her work. Psychic Causality that it is necessary to have an adequate knowledge of the nature of science to trace with methodical rigor the originarity of the buman experience and the God present in there. This will conduct science to a discovery of its own proper identity by the overcoming of the unconscious or conscious blocking before the revelation of God in the human soul. Hence, the present study offers a relevant contribution to the philosophical elucidation of a burning theological question today - a contribution achieved through an arduous interdisciplinary effort.
\end{abstract}

Key words: Original experience, anguish, God, science, Edith Stein.

\footnotetext{
* Doctora en Teología Dogmática. Entre sus múltiples publicaciones destaca Antropología Teológica. Acercamiento a la paradoja del hombre (2013, $3^{\text {a }}$ edición). El presente estudio es el resultado de la investigación interdisciplinar Proyecto Fondecyt Regular No 1160122 "Angustia inconsciente de encontrarse con Dios: Aproximación sistemática a los comentarios de Edith Stein a Teresa de Ávila y Martin Heidegger, comparados con el pensamiento de Victor Frankl”.
} 


\section{INTRODUCCIÓN}

Si bien la experiencia pareciera representar un fenómeno humano simple (Krings, 1978), aunque enigmático (Pereña, 2009; Lehmann, 1978; Kambartel, 1972) propio del ser en el mundo ${ }^{1}$, que se caracteriza por su inmediatez interna (Knauss, 1972) en cuanto "información mediada" (Ayala, 1995: 142) ${ }^{2}$, la dilucidación filosófica de su "originariedad" entraña problemas de gran envergadura conceptual y metodológica (Amengual, 2007; Fernández, 2006). Sobre todo, Hume y Kant, han sido criticados por Husserl a través de "la pretensión de la fenomenología de esclarecer los fundamentos de todas las ciencias fenomenológicamente", (Husserl, 1952: 32) sobre la base de su constitución por el yo-sujeto (Claesges, 1972) y como tal dilucidado por Edith Stein (Müller, 1999) en su obra Causalidad Psíquica (Stein, 2005a; 2010) ${ }^{3}$, primera parte de la trilogía Beiträge ${ }^{4}$.

En efecto, en dicha obra, Stein discute problemas fundamentales de la cientificidad de la psicología naturalística de su tiempo respecto a la doble legalidad de causalidad y motivación (Beckmann-Zöller, 2010) que Stein (2005c) califica de ceguera incomprensible ante la realidad del alma, hasta tal punto que "cabe pensar que la causa de esa ceguera y de la incapacidad de llegar a lo profundo del alma, no reside simplemente en una obsesión en relación con algunos prejuicios metafísicos, sino en un inconsciente miedo (Angst) de encontrarse con Dios" (Stein, 2005b: 523).

$\mathrm{El}$ presente estudio pretende verificar esta afirmación a través de la siguiente hipótesis: "La angustia inconsciente de encontrarse con Dios impide a la ciencia alcanzar la verdadera identidad propia, al desconocer la experiencia originaria del ser humano en el mundo" 5 . Esta situación se superaría por un análisis adecuado de la experiencia de la angustia, en cuanto propia del espíritu finito anticipado por el Espíritu Infinito (Stein,

1 Edmund Husserl (1997) inicia su obra Ideen I, Kapitel 1, \&1 de la siguiente manera: "Natürliche Erkenntnis hebt an mit der Erfahrung und verbleibt in der Erfahrung. In der theorethischen Einstellung, die wir die "naturliche" nennen, ist also der Gesamthorizont möglicher Forschungen mit einem Worte bezeichnet: es ist die Welt". Ver al respecto Muñoz (1999).

2 "Toda experiencia, dice Paul Ricoeur, es una síntesis de presencia e interpretación. El fenómeno religioso no es vivido en estado puro por ningún sujeto, sino a través de mediaciones culturales" (Ayala, 1995: 142). Ver al respecto, Schaeffler (1987).

3 Cuando se hace referencia a la obra de Stein (2005a), Causalidad Psíquica, se citará el texto en español y en su versión en alemán Stein (2010).

$4 \quad$ Se discute la fecha de la elaboración de Causalidad Psíquica, sobre todo a partir de los estudios de Wulf (2015); Szanto (2015); Jani (2015).

$5 \quad$ Hipótesis de trabajo del Proyecto Fondecyt: "Angustia inconsciente de encontrarse con Dios: Aproximación sistemática a los comentarios de Edith Stein a Teresa de Ávila y Martin Heidegger, comparados con el pensamiento de Victor Frankl”. 
2005a). Se estudiará entonces la experiencia (Erfabrung) (Dennebaum, 2017b), distinta de la vivencia (Erlebnis) (Volek, 2017), en cuanto experiencia originaria (Saur, 1972; Sánchez, 2013), comprendida como elaboración de la latencia de Dios (Villacañas, 2016; Caballero, 2010; Riego, 2014; Arboleda y Castrillón, 2015), tal como Stein la describe en su obra Causalidad Psíquica (Caminada, 2015; De Resende, 2012).

De hecho, Stein no interrelaciona la experiencia directamente con la angustia en Causalidad Psíquica, pero sí pareciera que conecta la Angst (Dennebaum, 2017a; Stein, 2005a: 293; Stein, 2010:69) a la Furcht (Stein 2005a: 271. 294. 297.300; Stein 2010: 51; 70; 73; 75) de modo indistinto, en la medida en que trata de aclarar las preguntas sobre lo psíquico y la causalidad (Dennebaum, 2017a; Häfner, 1972). Stein (2004a), delimita el justo uso de estos conceptos a las ciencias exactas que, a diferencia de la filosofía, no se basa en la experiencia, siendo ésta una Wesensschau, pues cuenta con una certeza absoluta, a la vez que resalta los errores metodológicos con respecto a las ciencias de espíritu, en la medida en que reemplazan la causalidad por motivación (Ferrer, 2014; Bello, 2010; Meneses \& Larkin, 2002). En efecto, la angustia se encuentra ligada a la "toma de posición" (Stein, 2005a:271; Stein, 2010:51) y a un obviar el fiat que de este modo no se produce (Stein, 2005a:294; Stein, 2010:70), pero que paraliza la tensión originaria del quehacer científico no resuelta adecuadamente (Stein, 2005a:300; Stein, 2010:75). En este sentido, Stein aborda tanto la experiencia del ateo, carente del fiat (Stein, 2005a:26; Stein, 2010: 43), como también la experiencia de un extraño "descanso en Dios" (Stein, 2005a:298; Stein, 2010:73), en cuanto expresión de un fiat logrado, pero sui generis (Bouillot, 2014). Estos aspectos constituyen un valioso atisbo para esclarecer la experiencia originaria en vista de la angustia y sus implicaciones sobre el quehacer científico.

El presente estudio llevará a cabo tal esclarecimiento a través de una atención cuidadosa al método fenomenológico husserliano, empleado por Stein, pero adaptado a sus objetivos propios (Jani, 2015). En el Prólogo de Causalidad Psíquica, Stein expone los aspectos fundamentales del método de Husserl, a la vez que se distancia del maestro en puntos precisos, aunque permaneciendo en algunos puntos de acuerdo con su Maestro, en tanto la experiencia originaria adquiere toda su relevancia (Gonzáles, 2016; Karl-Heinz, 1988). La propuesta metódica steineana involucra, por ende, la experiencia originaria de lo psíquico, a la cual Stein retrocede "con sus

\footnotetext{
6 Para una intelección adecuada del tan discutido distanciamiento de Stein con respecto a Husserl en el debate respecto al realismo-idealismo y la no coincidencia de la postura de Stein con aquella que ocupan sus con-discípulos del círculo de Gotinga Munich, ver los resultados afinados de la investigación de Sepp (2015).
} 
descripciones precisas y análisis de la constitución de psyche y espíritu", creando "el fundamento conceptual para las ciencias de la psicología y del espíritu” (Beckmann-Zöller, 2010:33), cuyo estudio posibilita la verificación de la hipótesis de la presente investigación.

\section{LA EXPERIENCIA, CAUSALIDAD Y LO PSÍQUICO}

La experiencia emerge, desde la argumentación de Stein en el Prólogo de Causalidad Psíquica, interrelacionada con la intención de que "pretende, claramente, elaborar la doble legalidad, que actúa junto en un sujeto psíquico de esencia sensible-espiritual, causalidad y motivación" (2005a: 3; 2010:3). En la Introducción se refiere al estudio del tema de la causalidad psíquica con que se hallan relacionadas "cuestiones psicológicas muy importantes de carácter metafísico, gnoseológico y científico" (2005a:217; 2010:5). La autora sitúa así la vida psíquica humana entre determinismo e indeterminismo, de tal modo que "la cuestión de la vida psíquica del hombre - comprendida en su totalidad o solo en parte- se halla integrada en la gran conexión causal de la naturaleza" (2005a:217; 2010: 5). Esto pone en peligro la característica fundamental de la experiencia humana, su libertad (De Rus, 2014), que se encuentra expuesta a la necesidad, debido a que, según Stein,

Se entremezclan cuestiones varias y diferentes: unas veces se trata de la dependencia de la voluntad humana con respecto a la razón teórica; otras, de la dependencia de la voluntad humana con respecto a la voluntad divina; otras, finalmente, de la dependencia de dicha voluntad con respecto a la general legalidad causal (Stein, 2005a:217; 2010:5).

Esto significa para Stein un error científico respecto a temas que sobrepasan el ámbito de las ciencias exactas como el concepto de causalidad, lo cual sucede cuando la Psicología de su tiempo sitúa lo psíquico en el contexto único de la naturaleza (Beckmann-Zöller, 2010).

\subsection{La causalidad en el contexto único de la naturaleza}

La autora recuerda, en primer lugar, la postura de Hume respecto al concepto de la causalidad y su crítica destructiva en cuanto este empirista disuelve dicho concepto a partir de su método empírico, pero basado en una reflexión causal. Así,

para Hume no es la razón la que establece el nexo entre causa y efecto, sino exclusivamente la experiencia que, sin embargo, no produce una relación 
necesaria, sino solo una relación basada en nuestra fe ("belief" a diferencia de "faith") y costumbre. (Beckmann-Zöller, 2010: 37).

Respecto a Kant, quien "mostró más allá de Hume que con solo la experiencia no se podía demostrar el nexo entre pasado y futuro, ya que para cada demostración por medio de la experiencia (inconscientemente) es usada una ley de causalidad" (Beckmann-Zöller, 2010: 37), Stein (2005a) evoca la imposibilidad de mostrar la causalidad como una de las condiciones de posibilidad de la ciencia natural exacta. Según Stein (2005a), a Hume sólo se le puede superar en su propio terreno, es decir, si él parte de la naturaleza, tal como esta se ofrece a los ojos del observador ingenuo, cabe admitir que en esa naturaleza existe una vinculación causal, mientras que Kant desearía investigar de qué índole es la conciencia de esa vinculación y si es ésta es una vinculación racional, pero

Tan solo una teoría precipitada acerca de la naturaleza de la conciencia y especialmente de la experiencia, le impide encontrar las conexiones demostrables que él anda buscando, y le seduce al fin para que elimine de la interpretación los fenómenos que él había tomado como punto de partida y sin los cuales sería incomprensible todo su planteamiento del problema (Stein, 2005a:219; Stein, 2010:7).

Si Kant no es capaz de responder al genuino problema epistemológico, que emerge de Hume, Stein (2005a) evoca la necesidad de un método de análisis y una descripción de los fenómenos que ofrece Husserl. Sin duda, con el estudio fundamental Ideas I y II, es decir, Ideas relativas a una fenomenología pura y una filosofía fenomenológica, Husserl (1952) ha abierto una posibilidad de superar las disyuntivas planteadas por Hume y Kant, de tal modo que el método fenomenológico parece proyectar un acercamiento acertado al fenómeno de la causalidad psíquica. La expresión parece, sin embargo, no asegura la certeza definitiva de obtener el resultado buscado, por lo cual Stein (2005a) propone emprender un acceso metódico nuevo al problema de la causalidad en cuanto fenómeno de la causalidad material a través de un análisis del concepto de lo psíquico.

\subsection{El concepto de lo psíquico según Edith Stein}

Stein (2005a) parte en su replanteamiento del concepto de lo psíquico desde la confusión reinante en los estudios entre conciencia y lo psíquico, para cuya clarificación ha contribuido el método fenomenológico. La autora, propone profundizar este resultado importante a través de lo que ella llama un haberse "desviado" del maestro (Stein, 2005a: 223; 2010: 11), que 
no la aleja de Husserl, sino que radicaliza la diferencia entre fenomenología y psicología, ya que ésta

es una ciencia 'natural' o 'dogmática', una investigación teórica de determinados objetos que hallamos en 'el mundo', en nuestro mundo, en el que vivimos y cuya existencia es el primer dogma y el presupuesto más evidente no indagado de todas nuestras reflexiones, pues 'En este mundo, además de cosas naturales y organismos vivos, encontramos seres humanos y animales, que, aparte de lo que tienen en común con las cosas y los simples seres vivos, muestran también ciertas características que los distinguen singularmente. A la totalidad de estas características la denominamos lo psíquico, y su investigación es tarea de la psicología (Stein, 2005a: 221; 2010: 9).

Esta argumentación husserliana conlleva una especial implicación respecto al concepto de "experiencia", que debe pasar desde una noción ingenua a un concepto científico. Para poder cumplir la tarea de la psicología, Stein (2005a) ve la necesidad de abordar metódicamente, con más detención, la constitución de los objetos en la conciencia. Pues, el mundo sobre el que recae nuestra mirada en su actitud natural, es el correlativo de nuestra conciencia, por lo que a cada objeto y a cada género de objetos les corresponden conexiones de conciencia formadas de manera determinada. Inversamente, cuando se producen conexiones de conciencia formadas de manera determinada, entonces tiene que aparecer necesariamente una determinada objetualidad. Así lo afirma la doctrina acerca de la "constitución de los objetos en la conciencia. Una legalidad ideal reglamenta las conexiones entre la conciencia constituyente y los objetos constituidos" (Stein, 2005a: 221-222; 2010: 9). Entonces, la investigación de esta legalidad es la tarea de la fenomenología husserliana trascendental pura, de la cual Stein (2005a) se distancia por aproximarse directamente a las cosas mismas y concretar una reflexión sobre la conciencia.

\subsection{Lo psíquico steineano en diferencia con Husserl}

Stein, una vez dilucidada la causalidad, aborda lo psíquico en general, que solo atribuye al yo real, sus características y estados, no al Yo puro de la conciencia (Goto \& Borges, 2016; Rosales, 2012). La autora, según Beckmann-Zöller, "va más allá de Husserl, Ideas I, cuando comprende la conciencia en el sentido de lo noético como conciencia de correlatos de todos los niveles al cual pertenece lo psíquico y en el nivel más bajo las sensaciones" (2010: 38). Realiza así unos pasos metódicos que ella describe, primero, en un nivel inferior y luego en el nivel superior para llegar "final- 
mente a una conciencia constituyente última, que no se actúa ya en unidades constituidas: a la corriente de la conciencia original o corriente de la vivencia" (Stein 2005a: 223; Stein, 2010: 10). Será esta "conciencia original" que cabe dilucidar en cuanto "experiencia" evocada por Hume y explicada por Kant, de modo insatisfactorio, pero propuesta por Husserl en cuanto corrección de las dos posturas anteriores, aunque no logrado del todo.

2. EL ORIGINARIO “DE DÓNDE” DE LA EXPERIENCIA, LA ENERGÍA VITAL SENSIBLE Y EL YO

Cuando Stein (2005a) inicia su análisis de la conciencia a partir de la corriente original en cuanto puro hacerse, del cual no pueda preguntarse por medio de qué se genera, emerge dicha corriente en cuanto constituyente último de la experiencia originaria como un fluir direccionado hacia adelante, sin que se mencione el hacia atrás. Se trata de una generación, sin que se pueda identificar su causa, que no se niega, pero cuyas mediaciones dejan "abierta la inmediatez, que caracteriza la vivencia" (Volek, 2017: 109).

Por su parte, la originariedad es un concepto de una curiosa evolución semántica (Saur, 1972), la autora lo analiza en sus aspectos básicos en Causalidad Psíquica ${ }^{7}$, siguiendo a Husserl (Espinet \& Steffen, 2009) mientras que en Acto y Potencia (Stein, 2005d) presta mejor atención a lo "originario" en su índole tanto "original-originante", como "fundamentación-justificación".

\subsection{El originario "de dónde" en la oscuridad y el yo}

La índole "originaria" de la experiencia resulta inexplicable en lo referente al origen mismo de la corriente, pues "En ningún lugar de la corriente se concibe la aparición de una fase, procedente de la otra, como

\footnotetext{
$7 \quad$ En Psychische Kausalität aparece tres veces originär (Stein, 2010: 75-78), pero ninguna vez ursprünglich.

8 "Se plantea la difícil cuestión del significado de "originario", entre "original” y "originante", así como la no menos difícil del doble aspecto en el significado de "fundamentación": dependencia ontológica ("Gründung”) y justificación (“Begründung”), que recoge el doble significado del alemán "Grund” (fundamento-base-fondo, y razón). A decir verdad, no plantearse estas cuestiones es casi imposible para quien piense que el sentido de la fenomenología (de hecho, no solo de la fenomenología, sino que "mutatis mutandis" nos encontramos algo análogo en la mejor filosofía analítica) consiste en aunarlas sin sacrificar la una a la otra, y en integrar los dos aspectos semánticos de cada uno de los dos conceptos en cuestión ("experiencia originaria") sin sacrificar el uno al otro" (Pereña, 2009: 43).
} 
'un ser causado' por ella. Una fase fluye procediendo de la otra y el originario 'de dónde' permanece en la oscuridad” (Stein, 2005a: 224; 2010: 11); lo que requiere una mayor especificación de cómo fluyen las fases unas en otras, en cuanto única corriente que se va incrementando de manera constante en la contemporaneidad del haber transcurrido y sin embargo un quedar relegado en la corriente, en cuanto modo de existencia, propia de la posibilidad de que de nuevo se recurra a ello (Stein, 2005).

Stein sintetiza, después de haber abordado esta temática en lo referente a la vista, el oído, el tacto y el olfato, destacando el papel del único yo en la constitución de la única corriente a partir de las muchas del pasado vivo en el futuro, que en todo momento sienta brotar de sí nueva vida. "Esta coincidencia de vivencia de diverso género en una única fase actual es la clase más original y primordial de la asociación de vivencias" (Stein, 2005a: 228; 2010: 15); según la cual, "el acontecer causado en cuanto asociación por contacto y clarificada la causalidad en la esfera de la vivencia, como algo análogo a la causalidad que se da en el ámbito de la naturaleza física condiciona al acontecer causante y es imposible que este último trascurra sin efecto" (Stein, 2005a: 231; 2010: 17).

Según Stein (2005a), aquí tenemos una primera distinción entre la causalidad mecánica y la causalidad de la vivencia, que encontramos de nuevo, cuando estudiamos los sustratos del acontecer. Pero primero cabe plantear acerca de cómo las vivencias de diverso tipo subsisten las unas junto a las otras y a la vez qué es lo que las separa y qué es lo que, vuelve a asociarlas en la unidad de una corriente. De hecho, las vivencias se distinguen según géneros muy distintos como sensación de color, de sonido, la sensación de hallarse, pero "yo me encuentro" siempre de algún modo y también en el estado enteramente determinado, no hay algo así como un "no-encontrarse" (Stein, 2005a: 232; 2010: 16).

Sin embargo, no solo es importante para Stein la relación causal como una concatenación de vivencias, sino que le interesa también analizar "su estructura, a fin de ver si esta constituye quizás los sustratos del acontecer causal, en forma análoga a lo que sucede con las cosas de la naturaleza exterior" (Stein, 2005a: 232; 2010: 16). De hecho, en toda vivencia se distingue, primeramente, un contenido que es recibido en la conciencia, como por ejemplo, un dato relativo al color o un sentimiento de bienestar. Cuando Stein (2005a) afirma que la vivencia de ese contenido y su acogida en la conciencia van acompañadas y por eso la vivencia misma es designada también como conciencia, hace una distinción importante entre contenido, vivenciar el contenido y la conciencia del vivenciar (BeckmannZöller, 2010). Pero Stein añade: 
En el ámbito de los contenidos de la vivencia existe una diferencia radical: la diferencia entre los datos extraños al yo (los datos de sensación) y los datos 'yoicos' (como es la sensación de bienestar). (...) Los unos se hallan frente al yo, los otros se encuentran del lado del sujeto. Si contempláramos objetos trascendentes, entonces hallaríamos en ellos una diferencia correspondiente: hay objetos a los que idealiter corresponden vivencias con contenidos extraños al yo, y hay otros objetos para cuya captación adecuada se precisa una vivencia con contenido yoico. Por un lado se hallan las 'cosas', por el otro lado se hallan, por ejemplo, los valores (Stein 2005a:232; 2010:18).

Una vez explicada las diferencias de la vivencia en cuanto el tener sensaciones, el sentir estados del yo y las diferencias de tensión de un contenido extraño del yo, o estar integrado a un contenido yoico, Stein (2005a) advierte que entre los componentes de la vivencia, el hecho de vivenciar es el que queda en primer lugar más afectado por la condición y los cambios de la esfera vital:

Sin embargo, no es el frescor el que suscita tal vitalidad. El frescor es como una fuente que mana continuamente, de la que brotan intensas y serenas oleadas de vivencias; el estado febril es como un surtidor incesante, que impulsa hacia adelante la corriente de la vivencia, se convierte en un placentero cansancio, que hace que la corriente se detenga y la bloquea contra influencias exteriores (...) En tal estado llegan hasta nosotros eventuales impresiones, que nosotros no podríamos tener en absoluto en otras ocasiones, y este enriquecimiento de la vivencia puede aparecernos precisamente como una intensificación de la vida, pero que nos llama a engaño acerca del 'verdadero' estado en el que nos encontramos (...) Esta diferenciación entre estados 'verdaderos' y 'aparentes', que aquí se impone, nos obliga a ir más allá de la esfera en la que hemos realizado hasta ahora nuestras reflexiones, y adentrarnos en un terreno enteramente nuevo en el horizonte de nuestra investigación (Stein 2005a: 235; 2010: 20).

La causalidad en el ámbito de la esfera es, según Beckmann-Zöller, (2010), un analogon de la causalidad en el ámbito de la naturaleza física y precisamente el caso fundamental de la causalidad (a la cual la física trata de reducir todas las relaciones causales). De este modo, los cambios en la esfera vital producen cambios en el sentimiento vital, y con esto en el vivenciar. Por eso, Stein diferencia las notificaciones de frescor, cansancio, super alerta y sensibilidad y toca así la esfera vital, central y general, en la cual se da el acontecer causal en el hombre y entre los hombres. 
2.2. Lo psíquico, consciente-inconsciente y la energía vital

Stein advierte la importancia de la relación de la conciencia y lo psíquico, cuando afirma: "Los estados vitales de seres conscientes suelen manifestarse en la conciencia, y semejante conciencia de un estado vital, su llegar a ser vivenciado, es un sentimiento vital" (Stein 2005a: 23; 2010:21) respecto al cual "es también posible que surjan estados vitales sin que se manifiesten en sentimientos vitales", es decir, sin que "el yo mismo nada sepa de ello" (Stein 2005a: 23; 2010: 21). De ahí que "cuando en un sentimiento vital llega la conciencia, no hay que confundir ese concienciarse con el contenido inmanente o con la conciencia de ese vivenciar, que es inherente a él como momento constitutivo" (Stein 2005a: 236; 2010: 21). Pues, "Como en las sensaciones de colores se manifiesta como su estado óptico momentánea así también en el sentimiento vital se manifiesta una condición momentánea de mi yo —su estado vital—y en el cambio de tales condiciones se manifiesta una cualidad real permanente: la energía vital" (Stein 2005a: 237; 2010: 21s).

Para Stein (2005a) la energía vital - Lebenskraft - es un concepto fundamental en la constitución del hombre al interior de la esfera vital, por la cual se distingue el yo psíquico como una característica permanente real. El yo que se encuentra en posesión de esa cualidad real, no debe confundirse con el yo puro que es portador de sus cualidades. De este modo:

El yo real lo designaremos lo psíquico y veremos que la conciencia y lo psíquico son sustancialmente diferentes lo uno de lo otro - la conciencia es el ámbito del vivenciar puro y consciente-, lo psíquico es el ámbito de la realidad trascendente que se manifiesta en las vivencias y en los contenidos de las vivencias (...) Como el acontecer propiamente causante no nos aparecen ya los sentimientos vitales, sino los modi de la energía vital que se manifiestan en ellos, es posible que aquí se realicen engaños (Stein 2005a: 238; 2010: 22).

La autora concluye que ha hallado un sustrato real de acción y la energía vital en cuanto lugar singularísimo en la constitución de la psique.

2.3. La energía vital y su lugar singularísimo en la constitución de la psique

La energía vital -Lebenskraft-, que designa la relación fenomenal dependiente de las vivencias de la corriente general de vivencia, en la cual se manifiesta el estado del yo, es un concepto steineano criticado con frecuencia, en el sentido de que la autora "abandonaría con su aceptación del pensamiento de Dilthey desde la filosofía de la vida y del vitalismo el suelo 
del concepto exacto" (Beckmann-Zöller, 2010:40). En efecto, una posibilidad de traducir Lebenskraft es la de un potencial para actuar Betätigungspotential (Betschart). Otra posibilidad, más certera, emerge desde el contexto del uso del concepto (Beckmann-Zöller, 2010), en cuanto conduce al centro del análisis steineano de la persona: "Todo el acontecer psíquico causal se puede comprender como una transposición de la energía vital Lebenskraft a la acción actual de vivenciar" (Stein, 2005a:241; 2010:25). El acontecer causal propiamente tal no son entonces los sentimientos vitales, sino los modos de la Lebenskraft, que se manifiestan en ellos. Los sentimientos son más bien la expresión de ellos, un contenido inmanente a la conciencia en el cual se dan a conocer los estados vitales del yo psíquico.

El ámbito de la esfera vital constituye, entonces, el sustrato de la corriente de la vivencia, a la que sostiene y de la que nace. La relación de esfera vital y la conciencia, la corriente de vivencias, aquí solo se indica. Lo psíquico es vivido por el yo en la introducción de energía y el desgaste de energía. Según Stein:

El hecho de que se proporcionen o se sustraigan energías a la energía vital es la causa del acontecer psíquico. El efecto consiste en los cambios de las demás cualidades psíquicas. No existe una dependencia causal directa entre otras cualidades entre sí, sin que exista una mediación de la energía vital (...) Todo acontecer psíquico está condicionado de modo causal pero no producido, sólo y exclusivamente, de modo causal. (Stein, 2005a: 239.246.251; 2010: 24.29.34).

Mientras la Lebenskraft, en Sobre la empatía (Stein, 2004b) todavía es llamada "fuerza psíquica" (Gibu, 2004), ya no es para Stein ahora -contrariamente a su análisis en Einfüblung - un "quantum finito", aquí la Lebenskraft es un continuum de cualidades, en el cual, sin embargo, se pueden distinguir intensidades. Pese a que las leyes causales psicológicas son vagas, expresan interrelaciones evidentes y pueden ser aplicadas en la sabiduría vital de la vida: "La experiencia de una determinada manera de cansancio durante la tarde muestra la incapacidad de leer un libro exigente. A la luz de una determinada intensidad de cansancio o de frescor puede hacerse pronósticos. Esto no significa que se puede predecir la totalidad de las acciones humanas" (Beckmann-Zöller, 2010: 41).

Una vez analizada la receptividad del sujeto y la distinción de la causalidad psíquica de la física por la contemplación. Stein (2005a) abre nuevas perspectivas, cuando insiste en "las relaciones causales fenoménicas y reales, si consideramos el ámbito de la actividad, que hasta ahora no habíamos tenido en cuenta en absoluto" (Stein, 2005a: 240; 2010: 25). Ofrece así un "análisis de la causalidad en el ámbito limitado de nuestro estudio 
- la esfera vital es lo condicionante y aquello de lo que depende el ritmo y la coloración del acto de vivenciar"' (Stein, 2005a: 240; 2010: 25). Por consiguiente, la energía vital y sus modi ocupan un lugar singularísimo en la constitución de la psique.

Una idea clara acerca de esta constitución de las vivencias no se puede alcanzar dentro del ámbito de la pura pasividad, pero si se dan analogías existentes entre la causalidad psíquica y la física, pues:

Todo lo que surge en la corriente de la vivencia se halla bajo condiciones causales, porque es concebible una conciencia en la que no surjan sentimientos vitales y fluya con una corriente y un ritmo constantemente iguales; en ella no habrá causalidad, es decir, condicionadas específicamente por la causalidad. El carácter de la corriente, como un continuo devenir, implica así una diferencia con respecto a la naturaleza física. Todo lo que en los estados psíquicos llegue a la existencia lo hace gracias a energía que toma de la energía vital; tiene en ella el fundamento de su existencia y mientras exista, se mantiene por ella (Stein, 2005a: 243; 2010: 26).

Esto sucede según las leyes causales y determinación de lo psíquico, es decir, la ley general "Todo acontecer psíquico está condicionado de modo causal" (Stein, 2005a: 246; 2010: 30) no basta para decidir acerca de la cuestión de la determinación de lo psíquico o decidir si el correspondiente estado se halla determinado clara y distintamente por la serie de estados precedentes y si es calculable a partir de ellos. Para esto habría que considerar primeramente si el acontecer psíquico se halla determinado de manera únicamente causal, o si habrá que hacer responsables también de su trascurso a otros factores. Los estados psíquicos no pueden derivarse, en cuanto a todo su contenido, de circunstancias causales:

Si yo soy capaz de recibir datos sensibles, y con qué intensidad esos datos se me imponen, eso depende del correspondiente estado de mi energía vital. Pero qué clase de datos surjan - si son colores o sonidos y qué colores especiales- eso es independiente de mi energía vital. Si esto pudiera determinarse con ayuda de leyes causales, entonces habría que mostrar que la receptividad de datos de distinto género es una receptividad distinta, y que además con la mínima diferencia de cualquier género - como en el caso de un color que tenga cualidad, luminosidad y saturación bien determinada- se asocia claramente una determinada receptividad. Sin embargo, tal ley de asociación no puede demostrarse que sea evidente ni puede probarse por ninguna clase de experiencia: posibilidad vacía. Otra posibilidad: a la misma receptividad le corresponden datos de distinto género y cualidad. La experiencia habla claramente a favor de esta segunda posibilidad (Stein, 2005a: 246; 2010: 30). 
Otro asunto sería si aquellos momentos del acontecer psíquico que están condicionados causalmente sin duda alguna, en los que se traspone de hecho la energía psíquica, admiten una determinación, es decir, un grado de tensión de vivencias. Aspecto que se refiere a la energía vital:

¿Es posible comprobar de manera clara e identificable la energía vital que exista en cada caso?... la energía vital ¿es un cuanto expresable numéricamente? La respuesta evidente es no: Los sentimientos vitales que se nos manifiestan son algo cualitativamente multiforme, que no puede reducirse a un denominador común, que no puede concebirse como compuesto por unidades iguales. Y lo mismo se aplica a los "rendimientos" de la energía vital, a los grados de tensión del acto de vivenciar. Incluso con su ayuda, no puede 'medirse' la energía vital" (Stein 2005a: 24; 2010: 31).

De este modo, todo sentimiento vital, que sirve como manifestación de la energía vital, es una cualidad peculiar y se podría distinguir entre las múltiples cualidades por medio de la atribución de nombre. Nuestro lenguaje, según Stein (2005a) se contenta con algunas distinciones, como frescor, cansancio, gran fatiga, suma excitación, sin embargo, hay que distinguir matices. Si esto fuera factible, entonces se podrían determinar leyes causales exactas, aunque no cuantitativas. Pero no hay duda alguna de que tales ideas individuales de sentimientos vitales no pueden deducirse, por tanto, las correspondientes leyes causales no pueden tampoco trazarse. Así, los sentimientos vitales y los grados de tensión que les corresponden constituyen un continuum de cualidades.

Como sucede con respecto a las cualidades distinguibles, también los géneros que están ordenados sobre ellas deben reconocerse como tales, el género sentimiento vital, que abarca todos los sentimientos vitales posibles, el género tensión del acto de vivenciar, al que pertenecen todos los grados de tensión y debe reconocerse con certeza totalmente indubitable y sin confundirlos unos con otros. De este modo:

En la diferenciabilidad de ciertas cualidades, que abarca una infinita variedad de cualidades con límites imprecisos, se basa la posibilidad de trazar leyes causales - aunque no sean exactas - con respecto al acontecer psíquico, leyes que serán análogas a las reglas causales físicas, con las que trabaja la experiencia precientífica. En la vida cotidiana nos servimos constantemente de tales reglas causales: ejemplo, visibilidad. Humedad del aire. Hay probabilidad, vaguedad -hechos ¿involucran el futuro, el presente, el pasado?" (Stein, 2005a: 250-251; 2010: 33-34).

Esto permite reconocer el campo de la actividad del yo, lo cual lleva a la autora a dilucidar la experiencia originaria en su interrelación con la vida 
espiritual, la motivación y toma de posición en cuanto experiencia religiosa.

\section{LA ENERGÍA VITAL ESPIRITUAL, MOTIVACIÓN, TOMA DE POSICIÓN Y EX- PERIENCIA RELIGIOSA}

Lo espiritual, contrario a la pasividad de lo psíquico, se caracteriza por la actividad e intencionalidad, ya que el yo "abre su mirada espiritual hacia y se dirige a algo —etwas, objetos" (Stein 2005a: 252; 2010: 35). Esta separación esquemática entre pasividad (pura esfera de vivencia) y leyes causales, por un lado, y actividad (espiritual y ámbito intencional) y motivación, por otro lado, no corresponde, sin embargo, a la realidad, de tal modo que Stein la relativiza (Beckmann-Zöller, 2010). Para la autora, espíritu significa "salir de sí mismo, apertura en el doble sentido: para un mundo objetivo, que se vivencia (erlebt wird). En esta interrelación Stein (2005a) no habla ya de leyes causales, sino de motivaciones, entendiendo por motivación la vinculación de actos espirituales. Para ella, junto con el equivalente lingüístico "tal como" - Weil-So-, es decisiva la igualdad formal de la estructura de la vivencia para su elección del concepto "motivación", que se encuentra en la oscuridad y recién por los análisis reflexivos debe salir a la luz (Beckmann-Zöller, 2010). Sin embargo, en los ámbitos de lo inconsciente o preconsciente - conceptos que Stein no usa-, se puede reconocer la misma estructura como en la motivación consciente.

\subsection{Vida espiritual y motivación}

\section{Según Stein:}

Hasta ahora nuestra investigación se ha desarrollado en un nivel abstracto. Ahora cambiamos de perspectiva y nos dedicamos a estudiar un nuevo ámbito de fenómenos. El yo, que hasta este momento vivía en el flujo de los datos, de los cuales 'se halla en posesión' sin mirar hacia ellos, abre ahora su mirada espiritual y se 'dirige' hacia algo que se presenta ante él en 'objetos"' (Stein, 2005a: 252; 2010: 35). "Los datos inmanentes poseen ya una forma inferior de intencionalidad, y correlativamente de objetividad. El dirigirse hacia algo, que es fundamento de los datos inmanentes, indica una nueva clase de vivencias, de unidades, que se constituyen en la corriente: la clase de las "aprehensiones" o de los "actos" (Stein, 2005a: 252; 2010: 35)?.

\footnotetext{
$9 \quad$ Según Stein: “El término 'acto' se entiende aquí en el sentido amplísimo de la vivencia intencional, no en el significado del hacer específico” (2005a: nota 28).
} 
Con ellos comienza la autora desarrollando la vida espiritual, en cuanto considera que la dirección de la mirada del yo puede ser diversa, es decir, puede ser una mirada retrospectiva hacia la vivencia que acaba de trascurrir, o que sea ahora una sensación o incluso un acto. En ese caso hay una reflexión:

Pero la mirada, en vez de dirigirse a un dato de sensación, puede dirigirse a través de él hacia algo que no pertenece ya a la corriente misma, sino que únicamente por medio de esa mirada del yo y de su lugar en la corriente, mantiene su relación con la conciencia individual $-\mathrm{y}$ con un determinado lugar en su corriente- y se dirige entonces hacia un 'objeto exterior', hacia un trascendente. En lugar del dato de sensación se presenta una 'imagen fluctuante', una forma coloreada, un tono que suena 'fuera de mí', 'allá en el exterior' (cualquiera que sea la espacialidad de este 'allá en el exterior'). En el ámbito de los actos surgen ahora nuevas formas de vinculación, que no habíamos encontrado todavía hasta el momento" (Stein 2005a: 253; 2010: 35).

Ahora bien, si la mirada se dirige sucesivamente hacia una serie de datos que trascurren de manera continuada o, más bien, a través de ellos se dirige hacia objetividades exteriores, entonces no solo hay una sucesión de aprehensiones separadas de imágenes singulares, sino también una aprehensión continuada. Según Stein (2005a), se tratra de añadir lo que sigue a lo anterior ("aprehensión"), un sintetizar las distintas aprehensiones ("síntesis") y un ser puestas en "movimiento" las posteriores por las anteriores ("motivación"). Todo esto tiene sentido únicamente en el ámbito de los actos del yo del percibir, del captar y del mover y no puede hablarse en la esfera de la pura pasividad.

Además, afirma Stein (2005a), si la vinculación de actos, a la que estamos refiriéndonos, la designamos en términos muy generales como motivaciones, entonces somos conscientes de que nos desviamos de la manera corriente de hablar, que limita esta expresión al terreno de los actos libres, especialmente a los de la voluntad. Pero nosotros creemos que esta ampliación tiene su buena razón de ser; que aquello a lo que ahora nos encaminamos, es una estructura general que tiene aplicación a todo el sector de las vivencias intencionales, una estructura que únicamente experimenta configuraciones distintas en relación con la particularidad de los actos. Sobre la necesidad de la ampliación del concepto de motivación, también la motivación en sentido tradicional tendría que corresponder a semejante configuración especial. 


\subsection{Motivación y aprehensión}

Si bien Stein (2005a) distingue tres fases de la vida espiritual: la aprehensión, la síntesis y la motivación y no diferencia entre razón y entendimiento -Verstand und Vernunft-, sino que usa generalmente entendimiento -Vernunft $-{ }^{10}$, cabe detenerse en la aprehensión "Apperzeption" (Espinet \& Steffen, 2009), y su relación con la motivación. La motivación, según Stein (2005a),

Es la vinculación que conecta a los actos unos con otros: no se trata de una mera fusión, como la de las fases de la corriente de la vivencia, que trascurren simultánea o sucesivamente, o como el enlazamiento asociativo de las vivencias, sino que es un proceder de lo uno partiendo de lo otro, por razón de lo otro. La estructura de las vivencias, que son las únicas que pueden entrar en la relación de la motivación, es absolutamente decisiva para la esencia de esta relación; se trata de actos que tienen su origen en el yo puro, que proceden fenoménicamente de él y que se encaminan hacia algo objetivo. El "pivote" en el que se apoya en cierto modo la motivación, es siempre el yo. El yo realiza un acto, porque ha realizado ya otro acto. La "realización" no debe entenderse todavía en el sentido de una auténtica espontaneidad. Es característico de la relación de motivación el que esta relación pueda surgir en diversas formas: puede realizarse explícitamente, pero puede darse también de manera únicamente implícita. Un ejemplo es la conclusión a partir de premisas" (Stein 2005a: 253s; 2010: 35).

De este modo, Stein (2005a) plantea que la aprehensión de una cosa, en cuanto tal, está desencadenada ya por un trascurso de índole determinada de datos sensibles; ese desencadenamiento se puede designar como una forma inferior de motivación, de igual manera que el tener sensaciones se considera una forma inferior de la intencionalidad. Dentro de esta aprehensión resaltan aquellas genuinas relaciones de la motivación, puesto que, si yo capto una cosa extensa en el espacio, percibo también con ella el lado posterior, que yo no capto por sí mismo, y esa co-aprehensión puede motivar la realización del movimiento libre, que hace que resalte el lado posterior co-aprehendido en una genuina percepción. Así:

La manera peculiar del darse de un objeto puede aprehenderse también como motivo para una toma de posición del yo ante este objeto, la dación perceptible, por ejemplo, como motivo para creer en su existencia. También

10 Los motivos son subdivididos en motivos de intelecto - Verstandes- y estímulo -Reiz-, en los cuales se investiga la relación de la fundamentación racional. Si hay solo una vinculación comprensible, se trata de un estímulo, no de un motivo racional (Beckmann-Zöller, 2010). 
aquí tenemos una vivencia intencional que tiende desde el yo hacia el objeto, y que en este sentido es realizado por él, sin ser una acción libre del yo. La creencia en la existencia puede ser a su vez motivación para la aserción que juzga de esa existencia, con que entramos ya en la esfera de la pura espontaneidad. Además, la existencia de un estado de cosas puede motivar la creencia en la existencia de otro estado de cosas (Stein 2005a: 255; 2010: 37).

Stein (2005a) afirma que si se contempla el asunto desde el valor de las cosas se podría afirmar que lo que motiva propiamente no es la realización del acto de partida, sino el contenido de sentido de ese acto, y para él se reservar la denominación de motivo, así, "el relámpago se convierte para mí en el motivo para esperar que se produzca el trueno, no la percepción del relámpago; motivo de mi gozo es la llegada de la anhelada carta, no el conocimiento de su llegada" (Stein, 2005a: 256; 2010: 38). Con los actos y sus motivaciones comienza, en palabras de Stein (2005a), el reino del sentido y de la razón, dándose así la rectitud y la falsedad, la evidencia y la noevidencia en un sentido del cual no puede hablarse en la esfera de la conciencia sin actos. De esta manera:

Yo puedo 'darme cuenta' -como una necesidad esencial- de que el trascurso de toda la acción de vivenciar es influido por el cambio de los sentimientos vitales, pero esta transformación no se realiza en virtud de la otra, como sucede en el caso de la motivación. En una de las esferas tenemos un acontecer ciego, en la otra tenemos una acción vidente, o por lo menos - en el caso de la motivación implícita - un acontecer que puede desembocar en una acción vidente. La evidencia en una de las esferas es el conocimiento de la necesidad del acontecer; la evidencia en la otra esfera es la realización con posterioridad del acto de ver original" (Stein, 2005a: 259; 2010: 40).

Stein concluye su dilucidación del reino del sentido y de la videncia, de indudable raigambre husserliana (Ales, 2015). Lo que se ha dicho aquí sobre el carácter de la motivación, encuentra su aceptación si se refiere al terreno de los actos específicamente lógicos, en el cual, por medio de procedimientos deductivos y probativos, se avanza hasta llegar a conclusiones. Esto aparece claro también en cuanto se refiere a la esfera de la praxis, en la cual un sentimiento pone en marcha una acción. Esto constituiría una consecuencia razonable y un procedimiento evidente. Pero "¿qué pasa en el caso del que hemos partido (ateniéndonos a la sucesión de niveles en la constitución)? Una simple percepción no es ni un proceso deductivo ni una acción de la voluntad (aunque algunas construcciones filosóficas lo consideran asî)" (Stein, 2005a: 259; 2010: 41), sino que entra en juego una toma de posición, que es decisiva para la experiencia originaria en cuanto experiencia religiosa. 


\subsection{Toma de posición y experiencia religiosa}

Los actos espirituales se fundamentan por un tomar conciencia pasivo (si el inicio era un estímulo, no un motivo racional), pero que es motivado. Luego sucede una inclinación activa hacia lo percibido y una toma de posición, que nuevamente acontece arbitrariamente, para lo cual sin embargo debe realizarse una toma de posición activa. A los actos espirituales pertenecen actos libres y actos sociales. Stein (2005a) designa como actos libres la convicción, la afirmación, el reconocimiento y el permitir. Actos sociales son afirmar, permitir, perdonar y fracasar. Los actos libres son motivados, fundamentan el comportamiento del sujeto, no se apropian -como las tomas de posición - del sujeto, sino que le dejan la libertad para aceptar o rechazar. Equivocaciones en relación con la motivación son posibles, como destacó Stein ya en Einfübrung. Cuando un motivo no es consciente sino una vivencia de trasfondo - Hintergrunderlebnis-, las motivaciones implícitas son una fuente de equivocaciones y errores; las explícitas, por el contrario, son el medio, para asegurar el dominio de la razón.

Según Stein, la actividad, interrelacionada con la motivación en cuanto explicación de la causalidad psíquica en el ámbito de las tomas de conocimiento, "en las cuales lo que es objetivo se convierte para nosotros en una dación: la percepción de una cosa, la captación de una realidad dada" (Stein 2005a: 260; 2010: 41), posibilita un "volverse hacia el objeto, del que ya se me concedió cierto conocimiento, y el progresar hacia ulteriores daciones. Las tomas de posición son algo de lo que se me hace 'partícipe'... 'Toman posesión de mí”' (Stein, 2005a: 261; Stein, 2010: 42).

Esto vale, específicamente, respecto de la fe religiosa, de la cual valga que: "yo no puedo anhelar para mí una fe religiosa, puedo esforzarme por ella con todas mis energías y puede ser que esa fe no se me conceda" (Stein, 2005a: 261; 2010: 43). Pero:

Existe una posibilidad que no se da en las simples tomas de conocimiento: puedo 'tomar posición' en un sentido nuevo, ante las tomas de posición; puedo acogerlas, situarme en su terreno, profesar mi creencia en ellas o comportarme con rechazo hacia ellas. Las acepto, es decir, me entrego a ellas, cuando surgen en mí, y lo hago gozosamente, sin resistirme. Las rechazo, esto no significa: las elimino. Eso no se halla en mi poder" (Stein 2005a: 261; 2010: 43).

No cabe duda de que Stein se refiere a la posibilidad de una experiencia de fe religiosa como fundamento imborrable de la certeza en cuanto otra certeza que la certeza simple de ser (Meis, 2017). Pero resulta importante que se trata no de un mero conocimiento, sino de una experiencia 
interrelacionada con los motivos del sujeto. De ahí que la autora explica que para la cancelación de una creencia se necesitan nuevos motivos, que quitan su vigor a los motivos de la creencia original y de los cuales la creencia vuelva a emerger por sí misma. Según Stein (2005a) esto lo explicita un ejemplo concreto:

Consideramos el caso de un ateo convencido de que, en una vivencia religiosa, siente íntimamente la existencia de Dios. No es capaz de sustraerse a la fe, pero no se sitúa en el terreno de la misma. No deja que esa fe llegue a ser eficaz en él; permanece inmutable en su 'concepción científica del mundo y de la vida', una concepción que caería por tierra si él aceptara abiertamente la fe (Stein, 2005a: 261; 2010: 43).

En este ejemplo directamente interrelacionado con la búsqueda del presente estudio, se aprecia la complejidad de la experiencia psíquica, que origina la certeza simple de ser en cuanto involucra no solo el sentir, sino también el querer del sujeto (Stein, 2005d).

Si bien se puede apreciar que Stein (2005a) comprende la experiencia interrelacionada con la toma de posición, la motivación y energía vital, que a su vez se articula desafiado por el impulso y la tendencia hasta latente, aunque dependientes del "fiat" de los actos libres, distingue dicha energía vital sensible y psíquica de la espiritual. De tal modo que, la energía vital sensible, por la cual la psique estaría arraigada en la naturaleza y recibe de ella fuerza, tendría influencia sobre la energía espiritual, que entonces estaría condicionada por el frescor corporal o el cansancio. La vida psíquica es un permanente desgaste de energía, en la cual se abren nuevas fuentes de energía.

Aquí Stein se topará con la experiencia "del-encontrarse -al finalde todas las fuerzas” (Stein, 2005a: 298; 2010: 73), que hace desembocar su explicación de la experiencia originaria en mayor profundidad en cuanto experiencia límite -al modo como hoy Sloterdijk habla de una situación de Grenzwert (Sloterdijk, 2013), y que Stein trata también en Einfübrung in die Philosophie, en referencia a "un poder espiritual", que luego explicita en cuanto "sentirse en manos de Dios" (Stein, 2004a: 171). La descripción de la experiencia originaria se abre entonces como posibilidad a encontrarse con Dios también para la Psicología en cuanto ciencia del espíritu, siendo Dios el "originario" por excelencia (Stein, 2005d), al cual Husserl también ya se trata de acercar. 
4. LA EXPERIENCIA DE DIOS, SU ORIGINARIEDAD Y EL QUEHACER CIENTÍFICO

Si bien la descripción de la experiencia de Dios en Stein (2005a) pareciera arrancar desde el primer indicio de su conversión a la fe católica (Betschart, 2013), poco tomado en cuenta, pero decisivo en vista de la relevancia de tal experiencia para el quehacer científico, la origenariedad de una tal experiencia debe estar también en la base de la ciencia, si esta se concibe en cuanto "consistencia objetiva", formulada por la literatura en el sentido de las palabras de Husserl (2008), citado por Edith Stein:

Solo en su literatura tiene la ciencia una consistencia objetiva; sólo en forma de obras escritas tiene una existencia propia, aunque llena de relaciones con el hombre y sus actividades intelectuales; en esta forma se propaga a través de los milenios y sobrevive a los individuos, las generaciones y las naciones. Representa así una suma de dispositivos externos, nacidos de actos de saber que han sido llevados a cabo por muchos individuos y que pueden convertirse de nuevo en actos semejantes de innumerables individuos" (Stein, 2005c: 625).

La ciencia emerge, entonces, desde experiencias subjetivas en cuanto existencia propia llena de relaciones con el hombre experiencias, cuya origenariedad se revela en cuanto religiosa, cuando la energía vital, sensible y espiritual es recibida desde una "fuente de energía, que se encuentra más allá del mecanismo de la personalidad individual, que afluye al yo volente, en la cual éste se halla anclado" (Stein, 2005a: 303; 2010: 78), una fuente más allá del yo, semejante a la experiencia del amor y del contacto con hombres de intensa vitalidad, que se ubica entre causalidad y motivación en cuanto situación límite.

\subsection{La situación límite de la Lebenskraft entre causalidad y motivación}

Cuando Stein analiza la "paradoja de la subjetividad humana: el alma está presente a sí misma en 'toda su peculiaridad' y sin embargo carece de su originario estar-consigo - ursprüngliches Bei-sich-Seins- propio" (GerlFalkovitz, 2015; Bénedicte, 2014), aborda la situación límite de los actos del ánimo - Gemütsakte-, que tienen una estructura diferente a los actos de afirmación racional y cuya comprensión la autora debe, en gran parte, según Müller (1992), a Reinach, en cuanto fenómeno originario de "vivencia -Erlebnis_- religiosa", que en su índole paradojal enigmática desafía la objetividad de la ciencia por sus características específicas de percibir 
-Wabrnehmen - la presencia de la absolutez de lo divino - noema- a través de la noesis del yo orante y pensante, en cuanto experiencia de dependencia, nulidad creatural y cobijo, vertida en confianza gozosa de certeza absolutamente cierta y agradecida por la entrega, al modo de Jesús, destacado por Reinach como por Stein sin que "la filosofía de la religión" se transforme en teología (Beckmann-Zöller, 2010).

De hecho, Stein admite, influenciada por Reinach, que "En el ámbito del ánimo el yo no vivencia algo — etwas- sino a si mismo - sich selbst - y con esto diferentes niveles del propio yo" (Beckmann-Zöller, 2010: 54). "Por eso, el Gemüt ocupa en Beiträge como en Einfühung, un lugar especial en la estructura de la persona humana" (Beckmann-Zöller, 2010: 61). Los actos del sentimiento - Gefühlsakte-, pertenecen a los actos espirituales o las mociones del ánimo - Gemütsbewegungen (Wertstellungnahmen)-, que contienen de modo diferente que los actos objetivos (percepciones, recuerdos, actos de pensar) una vivencia emocional. En efecto, según Stein (2005a) ellos involucran la energía vital - Lebenskraft - de tal modo que la pueden incrementar o disminuir. Los sentimientos como susto, angustia y tristeza privan al sujeto del frescor y de la vivacidad y paralizan el impulso de actuar.

Pese a que gracias a la esfera del ánimo - Gemüt-, la energía vital - Lebenskraft - se renueva con ayuda de contenidos espirituales, sucede que "Puedo emplear toda mi energía en abrirme un acceso, pero todo esfuerzo será inútil. Encontramos aquí en las capacidades de la persona una consistencia estable, que está sustraída al mecanismo causal. De este modo:

La energía debe distinguirse no solo de la capacidad receptiva como núcleo inmutable de las capacidades espirituales mutables, sino también de la energía vital sensible. Ambas no son suficientes para hacerme capaz de acoger determinados contenidos que requieren precisamente una propia energía vital espiritual. Es posible que yo posea la energía vital sensible que sea necesaria para el mantenimiento de cierta actividad espiritual, y que yo posea también capacidad receptiva para el correspondiente campo de objetos, un determinado ámbito de valores, y, sin embargo, no sea capaz de sentir vitalmente lo que ese ámbito me ofrece. (Stein 2005a: 297; 2010: 72).

Stein (2005a) ejemplifica esto, cuando insiste en reconocer el valor de una obra de arte, pero no se siente capaz de entusiasmarse por ella; o bien, reconocer la bajeza de unos sentimientos, pero no ser capaz de irritarme por ellos; reconocer el valor singularísimo de una persona, pero no ser capaz de amarla. Esta incapacidad para vivenciar contenidos de determinada importancia, el fracaso ante los requerimientos del mundo de valores conocido, que es compatible con el óptimo estado de energía vital sensible, 
revela que la energía vital espiritual es una energía impulsiva específica del acontecer espiritual. El que ella, a pesar de tal autonomía, dependa de la energía sensible, nos lo muestran ciertas relaciones causales fenoménicas que existen entre los procesos sensibles y los espirituales. De hecho, en un estado de agotamiento corpóreo-sensible, no logra experimentar un sentimiento de entusiasmo, pero este sentimiento se presenta inmediatamente, frente a la misma realidad, en cuanto yo me repongo. Si falta la energía vital espiritual desaparece también la posibilidad de que frescas energías impulsivas afluyan desde esos contenidos, y, por otra parte, desaparece también la posibilidad de un consumo tan intenso de energía vital, como el que requiere la vivencia de sus contenidos o de algunos de los mismos, como el temor o el duelo; "de tal manera que la carencia de energía vital espiritual significa eventualmente un ahorro de energía vital sensible" (Stein, 2005a: 297; 2010: 72). Se trata de una situación límite, que puede ser paralizada por la angustia, pero que también puede abrirse a lo que Stein llama el estado de reposo en Dios.

\subsection{La angustia y el "estado de reposo en Dios"}

Si bien la autora no integra el fenómeno de la angustia que brevemente aviva en su análisis y el correlato de la esfera del ánimo en el mundo de los valores, que caracteriza especialmente a la persona, ella admite que "Un suceso que se presenta como horrible ante mi vista, motiva en mí una tendencia a impedir que se produzca. El temor es temor vivo y la tendencia es tendencia viva. Pero el temor, como tal actúa paralizando mi actividad vital, y quita a la tendencia la energía para transformarse en acción" (Stein, 2005a: 294; 2010: 70). En el mismo sentido, Stein (2005a) comentará que existen como estados psíquicos, sin llegar a hacerse conscientes $\mathrm{Y}$ entonces a la energía motivadora se le añade la actividad causal de cada uno de los factores. El temor a un peligro impulsa (como motivo) a una acción defensiva. Se ve claramente lo que tendría que hacer para escapar de ese peligro, pero ese mismo temor es tan paralizador, que no puedo resolverme a adoptar ninguna decisión ni emprender acción alguna y sobreviene lo temido, sin posibilidad de defensa.

Este sobrevenir sin defenderme, Stein lo describe en cuanto estructura positiva, cuando advierte:

Además de esta afluencia de energías impulsivas, que presupone ya cierta medida de energía vital -a saber, la requerida para vivenciar los contenidos dispensadores de energía-, existe evidentemente otra afluencia que no está ligada a tal presupuesto y que prepara el camino hacia un imprevisto 'des- 
canso en Dios' (...) Existe un estado de reposo en Dios, de completa relajación de toda actividad espiritual, en el que no se hace ninguna clase de planes, no se adoptan resoluciones, y menos aún se actúa, sino que todo lo futuro se deposita en manos de la voluntad divina, 'se abandona' por completo 'al destino'. Este estado se me concede, por ejemplo, cuando una vivencia que sobrepasaba mis energías ha consumido por completo mi energía vital espiritual y me ha arrebatado toda 'actividad'. (Stein 2005a: 298; 2010: 73).

Tal descanso en Dios, es algo completamente nuevo y singularísimo, aquel silencio propio de muertos. En lugar de él, señala, surge "el sentimiento de hallarse acogido, de estar liberado de toda preocupación y responsabilidad y obligación de actuar y cuando yo me entrego a este sentimiento, comienza a llenarme poco a poco nueva vida y vuelve a impulsarme" (Stein, 2005a: 298; 2010: 73). Así, el único presupuesto para semejante renacimiento espiritual parece ser cierta capacidad receptiva, como la que se fundamenta en la estructura de la persona que se ha sustraído a la acción del mecanismo psíquico. Tal sustracción, sin duda, articula aquella originariedad de la experiencia del descanso en Dios, de tanta relevancia para el quehacer científico.

\subsection{La originariedad de la experiencia del "descanso en Dios" y la ciencia}

Si bien "Toda vida espiritual significa un consumo de energía vital sensible, incluso aquella vida espiritual cuyos contenidos traen consigo un incremento de impulsos espirituales" y "Más aún, puesto que la energía impulsiva inherente a un contenido aumenta cuando hay cierto aumento de su importancia, pero esa importancia exige a la vez una mayor tensión de energía a fin de ser vivenciada", " habrá que afirmar precisamente que cuanto más energía vital sensible se pierda, afluirá tanto más la energía espiritual" (Stein, 2005a: 295; 2010: 71). Este hecho llamativo evoca relaciones específicas, cuya investigación más profunda, según Stein, "nosotros no podemos fijarnos aquí como meta", ya que "conduce al terreno de la filosofía de la religión” (Stein, 2005a: 303; 2010: 78), propia de Husserl (Heesch, 1997). Pero sí, los rendimientos positivos y negativos (Stein, 2005a: 307; 2010: 81) de tales relaciones como también su despliegue poseen una originariedad, cuando se trata de la experiencia del descanso en Dios.

Pese a que para Stein la "motivación es un entramado de sentido en la que cualesquiera vivencias no pueden entrar unas junto a otras (Stein 2005a: 307; 2010: 81), y, sin embargo, puede producirse "una ruptura del curso de la experiencia" (Stein, 2005a: 311; 2010: 85). Por ende "Debemos 
estar siempre preparados para que el propósito haga irrupción en un lugar donde menos lo esperamos, y para que eche por tierra todo nuestro "conocimiento de los hombres" y todos nuestros cálculos" (Stein, 2005a: 311; 2010: 85) como también las "leyes asociativas", de las cuales habla Hume (Stein, 2005a: 312; 2010: 86). Con la alusión a Hume y las "leyes asociativas", Stein (2005a) vuelve al problema de la experiencia originaria, expuesto al inicio, $\mathrm{y}$ ahora dilucidado a través del aporte del yo concreto en la constitución de la realidad a lo largo de la argumentación de Causalidad Psíquica, pero sintetizado en el Anexo 1 en cuanto concepto de "ciencia" interrelacionado con las "conexiones de las vivencias" (Stein, 2005a: 330334; 2010: 100-104). De hecho, "Si consideramos las vivencias según su modalidad de realización y de realidad dada, entonces observaremos que hay en su interior una diferencia fundamental: pueden dividirse - sin tener en cuenta su peculiaridad material- en vivencias originarias y en vivencias reproductivas" (Stein, 2005a: 313; 2010: 86). En el ámbito de la sensibilidad esta oposición coincide con la diferencia entre impresiones e ideas según el sentido en que las entiende Hume, y con la diferencia entre originariedad y no-originariedad según la manera de hablar de Ideas de Husserl y de especial relevancia para una auténtica ciencia.

Stein ejemplifica en que pese a que "Yo no puedo representarme una tesis como me represento un árbol o una casa o incluso el sentimiento de gozo" (Stein, 2005a: 314; 2010: 87) aquí existe la oposición entre la originariedad y la no originariedad en el sentido de la oposición entre la realización efectuada por primera vez y la realización repetida.

La realización original es aquella en virtud de la cual una claridad me ilumina por primera vez, un objeto categorial llega por primera vez a convertirse en el objeto. A esto se contrapone la repetición como reproducción, en la cual yo, por ejemplo, me aclaro de nuevo una proposición que ya una vez yo había entendido (...) En la medida en que las vivencias sensibles incluyen un hacer espiritual, permiten, además de la presentificación que únicamente es posible en ellos, las mismas variaciones que los actos categoriales" (Stein, 2005a: 314; 2010: 87).

En efecto, Stein (2005a), una vez sintetizadas las cuatro modalidades diversas de las vivencias: la realización original, la realización presentificante y la realización repetida, y el hecho de que un acto que recurre de nuevo llegue a convertirse en objeto, se detiene en las vivencias originales, al afirmar: ellas "emergen en la corriente como un primer comienzo (por ejemplo, como un dato sensitivo que se presenta) u otra cuya aparición está motivada por vivencia ya existentes. Los "primeros comienzos" no pueden deducirse, evidentemente, de la corriente del vivenciar anterior. Por 
lo demás, el trascurso de las vivencias originales, según la consistencia de su contenido está regulado por las leyes de la motivación, por cuanto no se trata de una vivencia condicionada de manera puramente causal (como en los impulsos). No puede hablarse aquí en absoluto de una regulación asociativa, porque esta solo puede tenerse en cuenta, en el ámbito de la vivencia reproductiva.

La distinción entre "vivencias reproductivas" y "vivencias originales", aunque "motivadas" en cuanto "asociación por contacto", es decir, el nacimiento de conexiones en el trascurso original de la vivencia es el fundamento de que, en lo sucesivo, una parte de tal conexión pueda llegar a convertirse en estímulo o en motivo para efectuar progresos en esa conexión. Por tanto, los trascursos asociativos quedarían caracterizados como trascursos motivados, mientras las "vivencias reproductivas" patentizan la tarea de la ciencia de prestar atención a su índole propia no "originaria". La ciencia no solo debe respetar esta originariedad en cuanto fundamento último de todo cuanto existe, sino también decidirse ante ella para lograr su propia identidad de ciencia en el sentido husserliano. Pues, solo así la ciencia logra su "consistencia objetiva", orientada por la verdad de "las cosas" mismas, pero constituida por el "yo real”, que, según Stein, a diferencia del "maestro", decide libremente sobre la aceptación o el rechazo de dicha originariedad. La originariedad de la experiencia aporta entonces una relevancia crítica a la ciencia, que se distancia de Husserl, pero está en continuidad profunda con él y como tal corrige la ingenuidad con que Hume invoca tal experiencia en cuanto decisiva para el quehacer científico moderno y como lo plasma también el intento fallido de una fundamentación de la Psicología exacta por Münsterberg.

En definitiva, puede concluirse con Stein, que la "nueva fuente" de energía espiritual, de la cual emana el reposo en Dios en cuanto experiencia originaria del "espíritu subjetivo", que se constituye en cuanto "espíritu objetivo", desafía el quehacer científico, si este pretende ser ciencia en el sentido husserliano. Pero más todavía cuando el Espíritu divino anticipa al espíritu humano la "experiencia religiosa" articula un cese de actividades psíquicas para un renacer originario, cuya fuente Stein recién identifica por la fe en su obra maestra Ser finito y ser eterno.

\section{A MODO DE CONCLUSIÓN}

Pueden apreciarse los primeros atisbos de la experiencia originaria en cuanto eje articulador del conflicto de Stein con la Psicología del siglo XIX para superar las lagunas metodológicas abiertas por Hume y Kant, gracias a la fenomenología en cuanto ciencia exacta de Husserl, aplicada por Stein en continuidad discontinua con el maestro, por una atención especial al 
papel del yo real de la vida espiritual sensible, interconectado con la energía vital por la motivación. La verificación steiniana de esta verdad se avala por el análisis litero-lingüístico de "El Castillo Interior". De hecho, Stein aborda esta verdad en vista de una "Psicología sin alma" del siglo XIX y cómo ella adquiere su verdadera identidad de "ciencia del espíritu" si acepta el cuestionamiento de su cientificidad precientífica, basado en la constitución del ser humano en el mundo tal como las ciencias humanas actuales suelen admitir, con mayor o menor eficiencia, aunque todavía son constatables olvidos lamentables de la distinción de causalidad y motivación, sobre todo, cuando se trata del ámbito de la neurociencia.

En la comprensión steineana de la experiencia originaria se hace presente el fenómeno de la angustia, que puede experimentar el científico ante la toma de posición de sus pre-supuestos - toma de posición abordada en el comentario de Stein respecto a Martin Heidegger. Allí la experiencia originaria verbaliza el Dasein heideggeriano en cuanto encontrarse inconsciente en el mundo, que requiere ser sacado a la luz desde su estar oculto en la existencia humana y como tal expuesto al extraño acabamiento de la energía vital, que se revela en momentos menos esperados con certeza indudable, pero ante el cual el filósofo Heidegger como el científico ateo pueden retroceder y negar voluntariamente la validez de tal experiencia, cuya aceptación concreta podría conducirlos al logro de la auténtica identidad tanto de su existencia en el mundo cuanto en lo referente a la ciencia. Stein (2005a) no articula este logro, sino que se contenta con la invitación a tomar en serio la experiencia de fe, distinta de la experiencia originaria, pero no ajena a ella. Evoca sí los efectos del acabamiento de la energía vital sensible y el renacimiento inesperado de la energía vital espiritual en cuanto explicable solo por el actuar inexplicable de Dios, Espíritu Infinito, quien anticipa al espíritu finito, como lo explicita la autora, sobre todo, en Ser finito y ser eterno (Stein, 2005c).

En definitiva, la experiencia originaria verifica la Gemütsanticipation husserliana, Ideas I 24 en Stein (2005a), pero la explicación steineana por el acto libre del espíritu humano atestigua la salida de dicho espíritu hacia formas de la trascendencia que no son las de la conciencia solamente, es decir, de la trascendencia quad nos sino de una trascendencia in se, según la distinción de Angela Ales Bello que evoca Christof Betschart y que Eduardo Gonzáles de Pierro ve representada justamente por lo que Rubén Sánchez Muñoz llama experiencia originaria de Dios (Gonzáles, 2016). Tal experiencia, acreditada por Victor Frankl en cuanto "presencia oculta de Dios" "11, la define Sánchez (2013) como una instancia no externa o ajena a

11 Rodolfo Nuñez Sobre limites y posibilidades: La Angustia inconsciente de encontrarse con Dios en Victor Frankl, en prensa. 
la persona, sino como un reflejo directo y expresivo de su propia manifestación de trascendencia, como el enlace verdaderamente posible entre la dimensión del espíritu (Geist) y la auténtica salida de sí misma, a la que la persona estaría llamada hasta la última posibilidad, que estaría representada por la instancia de la mística en cuanto experiencia vivida (Bouillot, 2014).

\section{REFERENCIAS}

-Ales, A. (2002). El teísmo en la fenomenología: Edmundo Husserl y Edith Stein frente a frente. Devenires 3(6), 172-194.

-Ales, A. (2015). The Sense of Things Toward a Phenomenological Realism. New York: Analecta Husserliana.

-Amengual, G. (2007). El concepto de experiencia de Kant a Hegel. Tópicos (15), 5-30.

-Arboleda, C. \& Castrillón L. (2015). Experiencia originaria de Dios, desinstitucionalización y deconstrución de las religiones. Escritos 23(50), 83-108.

-Ayala, J. (1995). Fenomenología y experiencia religiosa. Investigaciones fenomenologicas, (1), 135-145.

-Beckmann-Zöller, B. (2010). Edith Stein, Beiträge zur philosophischen Begründung der Psychologie, Freiburg: Herder.

-Bello, A. (2010). Causality and Motivation in Edith Stein. En R.Poli (Ed), Causality and Motivation (pp. 135-149). Frankfurt, Paris, Lancaster: New Brunswide.

-Bénedicte, B. (2014). La liberté et ses Paradoxes d'Edith Stein. En C. Betschart, La liberté (pp. 51-73). Toulouse: Éditions du Carme.

-Betschart, C. (2013). Unwiederholbares Gottessiegel. Personale Individualität nach Edith Stein. Basel: Friedrich Reinhardt.

-Bouillot, B. (2014). La liberté et ses Paradoxes d'Edith Stein. En C. Betschart, La liberté chez. Edith Stein (pp. 51-73). Toulouse: Editions du Carmel.

-Breyer, T. (2009). Apperzeption. En F. Steffen, Husserl-Lexikon. Darmstadt: Wissenschaftliche Buchgesellschaft.

-Caballero, J.L. (2010). Ejes transversales del pensamiento de Edith Stein. Teología y Vida (51), 39-58.

-Caminada, E. (2015). Edith Stein's Account of Communal Mind and its Limits: A Phenomenological Reading. HumStud (38), 549-566.

-Claesges, U. (1972). Erfahrung, transzendentale. En J. Ritter (Hg.), Historisches Wörterbuch der Philosophie 2 (pp. 623-624). Berlin: Schwabe Verlag.

-De Resende C. (2012). Contribuições de Edith Stein para a epistemologia das ciências e para a psicologia cientifica. Tesis doctoral, Universidade de São Paulo FFCLRP_ Departamento de Psicología Programa de pos-graduação em psicología. Recuperado de http://www.teses.usp.br/teses/disponiveis/59/59137/tde11102013-150442/pt-br.php 
-De Rus, E. (2014). L'experience de la liberté chez Edith Stein: un approche de la vie intérieure. En C. Betschart, La liberté chez Edith Stein (pp. 27-50). Toulouse: Editions du Carmel.

-Dennebaum, T. (2017a). Angst. En M. Harald (Hg.), Edith Stein-Lexikon (pp. 109-111). Feiburg-Basel-Wien: Herder.

-Dennebaum, T. (2017b). Erfahrung. En M. Harald (Hg.), Edith Stein-Lexikon (pp.102-104). Feiburg-Basel-Wien: Herder.

-Espinet, D. \& Steffen, F. (2009). Originarität. En F. Steffen, Husserl-Lexikon. Darmstadt: Wissenschaftliche Buchgesellschaft.

-Fernández, F. (2006). Conversación, Diálogo y lenguaje en el pensamiento de Hans-Georg Gadamer, Anuario Filosófico, 39(1), 55-76.

-Ferrer, U. (2014). Comprender a Edith Stein. Madrid: Palabra.

-Gerl-Falkovitz, H. (2015). Unerbittliches Licht. Versuch zur Philosophie und Mystik Edith Steins. Dresden: Religionswissenschaft am Institut für Philosophie.

-Gibu, R. (2004). La empatía como problema de contribución en la obra filosófica de Edith Stein. La lámpara de Diógenes, (5), 43-56.

-Gonzáles, E. (2016). La fenomenología de Edith Stein como refutación del "realismo fenomenológico" del "Círculo de Gotinga". Stein y su interpretación del idealismo trascendental husserliano. En Acta fenomenológica latinoamericana 5 (pp. 27-41). Lima: Pontificia Universidad Católica del Perú.

-Goto, T. \& Borges, M. (2016). Contribuciones de la fenomenología de Edith Stein al problema mente-cuerpo. Apuntes para la Psicología. Investigaciones Fenomenológicas, (13), 65-87.

-Häfner, H. (1972). Angst. En J. Ritter (Hg.), Historisches Wörterbuch der Philosophie 1 (pp. 310-311). Berlin: Schwabe Verlag.

-Heesch, M. (1997). Religionsphilosophische Aspekte im Denken Husserls.Überlegungen zur Wissenschaftskonzeption und ihren religionsphilosophischen Voraussetzungen im Ersten Buch der Ideen zu einer reinen Phänomenologie und in den Cartesianischen Meditationen. Theologie und Philosophie, 1(72), 77-90.

-Husserl, E. (1952). Ideen zu einer reinen Phänomenologie und phänomenologischen Philosophie. Zweites Buch: Phänomenologische Untersuchungen zur Konstitution. Haag: Martinus Nijhaff.

-Husserl, E. (2008). Logische Untersuchungen. Berlin: Akademie Verlag -Jani, A. (2015). Individuality and Community. Construction of Sociality in Edith Stein's Early Phenomenology. Philobiblon, 20(1), 19-32.

-Kambartel. F (1972). Erfahrung. En J. Ritter (Hg.), Historisches Wörterbuch der Philosophie 2 (pp. 609-617). Berlin: Schwabe Verlag.

-Karl-Heinz, L. (1988). Die Phänomenologie Husserls und Edith Steins. Theologie und Philosophie, (63), 182-202.

-Knauss, G. (1972). Erfahrung innere. En J. Ritter (Hg.), Historisches Wörterbuch der Philosophie 2 (pp. 619-620). Berlin: Schwabe Verlag.

-Krings, H. (1978). Experiencia. En Conceptos Fundamentale de Filosofía II (pp. 8081). Barcelona, Herder. 
-Lehmann, K. (1978). Experiencia. En K. Rahner \& J. Alfaro (dir.), Sacramentum Mundi 2 (pp. 72-73). Herder: Barcelona.

-Meis, A. (2017). La certeza simple de ser y su relevancia hoy según Edith Stein. Revista Theologica Xaveriana, 183(1), 113-139.

-Meneses, W. \& Larkin, M. (2002). Edith Stein and the Contemporary Psychological Study of Empathy, Journal of Phenomenlogical Psychology, (43), 150-184.

-Müller, A. (1992). Grundzüger der Religiosnphilosophie Edith Steins. Freiburg /München: Verlag Karl Alber.

-Müller, A. (1999). Auf der Suche nach dem Ursprung der Erfahrung. Edith Steins Kritik am transzendentalen Ideaismus Edmund Husserls. En H. Rainer (Hg.), Metamorphose der Phänomenologie. Dreizehn Stadien von Husserl aus (pp. 136-169). Freiburg/München: Verlag Karl Alber.

-Muñoz, J. J. (1999). Afinidad estructural de las experiencias estética, ética, metafísica y religiosa. Tesis doctoral, Universidad Complutense, Madrid. Recuperado de https:/ /biblioteca.ucm.es/tesis/19972000/H/2/H2097001.pdf

-Pereña, F. (2009). Experiencia originaria y fundamentación. Investigaciones fenomenológicas, (6) 43- 52.

-Riego, I. (2014). Sobre el Dios de la experiencia, que viene al discurso de la razón. Open Insight, 5(7), 157-184.

-Rosales, D. (2012). "Yo puedo". El acto libre como experiencia originaria de la ética. En Acta fenomenológica latinoamericana 6 (pp. 257-269). Lima: Universidad Católica del Perú.

-Sánchez, R.(2013). La experiencia originaria de Dios en la fenomenología de Edith Stein. Analogia, (27), 121-134.

-Saur, I. (1972). Original, Originalität. En J. Ritter (Hg.), Historisches Wörterbuch der Philosophie 6 (pp. 1373-1378). Berlin: Schwabe Verlag.

-Schaeffler, R. (1987). Logisches Widerspruchsverbot und theologisches Paradox. Überlegungen zur Weiterentwicklung der transzendentalen Dialektik. Theologie und Philosophie, 62(3), 321-351.

-Sepp, R. (2015). Edith Steins Position in der Idealismus-Realismus-Debate. En B. Beckmann-Zöller \& H. Gerl-Falkovitz (Hg), Edith Stein, Themen-KontexteMaterialien (pp. 17-27). Dresden: Text \& Dialog.

-Sloterdijk, P. (2013). Ausgewählte Übertreibungen, Gespräche und Interwiews 19932012. Suhrkamp: Bernard Klein.

-Stein, E. (2004a). Einführung in die Philosophie. Freiburg-Basel-Wien: Herder.

-Stein, E. (2004b). Sobre el problema de la empatía. Madrid: Trotta

-Stein, E. (2005a). Causalidad psíquica. En E. Stein Obras Completas, vol. II (pp. 217-329). Burgos: Monte Carmelo.

-Stein, E. (2005b). El Castillo Interior. En E. Stein Obras Completas, vol. V (pp. 80-106). Burgos: Monte Carmelo.

-Stein, E. (2005c). Ser finito y ser eterno. En E. Stein, Obras Completas, vol. III (pp. 587-1112). Burgos: Monte Carmelo.

-Stein, E. (2005d). Acto y potencia. En E. Stein, Obras Completas, vol. III (pp. $225-$ 536). Burgos: Monte Carmelo. 
-Stein, E. (2010). Psychische Kausalität. En Beiträge zur philosophischen Begründung der Psychologie und der Geisteswissenschaften (pp. 1-109). Freiburg: Herder.

-Szanto, T. (2015). Collective Emotions, Normativity, and Empathy: A Steinian Account. Hum Stud, (38), 503-527.

-Villacañas, J. L. (2016). Latencia. La elaboración de la experiencia originaria. Diánoia, 61(76), 1-15.

-Volek, P. (2017). Erlebnis. En M. Harald (Hg), Edith Stein-Lexikon (pp. 109111). Feiburg-Basel-Wien: Herder.

-Wulf, C. (2015). Rekonstruktion und Neudatierung einiger früherer Werke Edith Steins. En B. Beckmann-Zöller \& H. Gerl-Falkovitz (Hg), Edith Stein, Themen-Kontexte-Materialien (pp. 249-266). Dresden: Text \& Dialog.

Sumario: Introducción; 1. La experiencia, causalidad y lo psíquico; 1.1. La causalidad en el contexto único de la naturaleza; 1.2. El concepto de lo psíquico según Edith Stein; 1.3. Lo psíquico steineano en diferencia con Husserl; 2. El originario "de dónde" de la experiencia, la energía vital sensible y el yo; 2.1. El originario "de dónde" en la oscuridad y el yo; 2.2. Lo psíquico, consciente-inconsciente y la energía vital; 2.3. La energía vital y su lugar singularísimo en la constitución de la psique; 3. La energía vital espiritual, motivación, toma de posición y experiencia religiosa; 3.1. Vida espiritual y motivación; 3.2. Motivación y aprehensión; 3.3. Toma de posición y experiencia religiosa; 4. La experiencia de Dios, su originariedad y el quehacer científico; 4.1. La situación límite de la Lebenskraft entre causalidad y motivación; 4.2. La angustia y el "estado de reposo en Dios"; 4.3. La angustia y el "estado de reposo en Dios"; A modo de conclusión; Referencias. 